\title{
RUANG PROYEKTIF KOMPLEKS SEBAGAI MANIFOLD KOMPLEKS BERDIMENSI 1
}

\author{
SILVIA OKTARINI, HARIPAMYU, SHELVI EKARIANI \\ Jurusan Matematika, \\ Fakultas Matematika dan Ilmu Pengetahuan Alam, Universitas Andalas, \\ Kampus UNAND Limau Manis Padang, Indonesia, \\ email : silviaoktarini20@gmail.com
}

\begin{abstract}
Abstrak. Manifold kompleks adalah suatu manifold smooth yang dilengkapi oleh struktur kompleks yang dapat ditentukan oleh suatu atlas holomorfik. Salah satu contoh dari manifold smooth adalah ruang proyektif kompleks $\mathbb{C P}$. Ruang $\mathbb{C P}$ didefinisikan sebagai himpunan dari semua kelas ekuivalen $[z]$ dengan $z \in \mathbb{C}^{2} \backslash\{0\}$. Penelitian ini bertujuan untuk mengkaji bahwa ruang proyektif kompleks $\mathbb{C P}$ merupakan manifold smooth dengan struktur smooth yang analog dengan yang ada pada $\mathbb{R P}^{3}$. Selanjutnya, akan ditunjukkan bahwa terdapat struktur kompleks pada $\mathbb{C P}$ sehingga $\mathbb{C P}$ adalah manifold kompleks berdimensi 1 .
\end{abstract}

Kata Kunci: Manifold Smooth, Manifold Kompleks, Struktur Kompleks, Ruang Proyektif Kompleks $(\mathbb{C P})$

\section{Pendahuluan}

Manifold adalah gambaran umum kurva dan permukaan pada berbagai dimensi yang secara keseluruhan memberikan konteks matematis untuk memahami "ruang". Teori manifold diperlukan pada sebagian besar bidang matematika murni dan berbagai bidang keilmuan lainnya [3]. Manifold paling sederhana adalah manifold topologi yaitu suatu ruang topologi dengan tiga sifat tertentu yang menggambarkan bahwa ruang tersebut secara lokal terlihat seperti suatu ruang Euklidis $\mathbb{R}^{n}$ [3].

Manifold smooth merupakan jenis manifold topologi baru dengan penambahan struktur tertentu. Struktur tambahan ini disebut struktur smooth. Kata smooth disini juga dapat diartikan sebagai terdiferensial. Pada kenyataannya, tidak semua manifold topologi yang memiliki struktur smooth artinya terdapat manifold topologi yang bukan manifold smooth [3]. Jenis manifold lain yang sangat dekat hubungannya dengan manifold smooth yaitu manifold kompleks. Manifold kompleks adalah suatu manifold smooth yang dilengkapi oleh struktur kompleks. Struktur kompleks ini dapat ditentukan oleh atlas holomorfik. [2].

Salah satu contoh yang sangat penting pada manifold kompleks yaitu ruang proyektif kompleks $\mathbb{C} \mathbb{P}^{n}$. Ruang ini merupakan ruang kuosien yang diperoleh dari $\mathbb{C}^{n+1} \backslash\{0\}$ dengan mendefinisikan suatu kelas ekuivalen pada $\mathbb{C}^{n+1} \backslash\{0\}$. Untuk $n=1$, ruang proyektif kompleks disebut dengan kurva proyektif kompleks. Secara geometris, $\mathbb{C P}$ digambarkan sebagai himpunan dari semua garis kompleks yang melalui titik asal pada $\mathbb{C}^{2}$. Pada penelitian ini peneliti tertarik untuk mengkaji ru- 
ang proyektif kompleks $\mathbb{C P}^{n}$ sebagai manifold kompleks untuk $n=1$.

\section{Landasan Teori}

\subsection{Relasi Ekuivalen}

Relasi adalah hubungan antara anggota suatu himpunan dengan himpunan lain. Pada sub-bab ini akan dibahas definisi dan contoh terkait relasi ekuivalen.

Definisi 2.1. [3] Misalkan $X$ adalah suatu himpunan tak kosong. Suatu relasi pada himpunan $X$ dikatakan relasi ekuivalen apabila bersifat:

(1) Refleksi, yaitu $x \sim x$ untuk semua $x \in X$.

(2) Simetri, yaitu jika $x \sim y$ maka $y \sim x$ untuk semua $x, y \in X$.

(3) Transitif, yaitu jika $x \sim y$ dan $y \sim z$ maka $x \sim z$ untuk semua $x, y, z \in X$.

Contoh 2.2. Suatu relasi $\sim$ pada himpunan $\mathbb{R}^{n+1} \backslash\{0\}$ yang didefinisikan oleh $x \sim y$ jika dan hanya jika $y=k x$ dengan $x \in \mathbb{R}^{n+1} \backslash\{0\}$ dan $k \neq 0$ dimana $k \in \mathbb{R}$ adalah suatu relasi ekuivalen.

Definisi 2.3. [3] Misalkan $\sim$ adalah relasi ekuivalen pada X, maka kelas ekuivalen dari $x \in X$ ditulis, $[x]$, adalah himpunan semua $y \in X$ sedemikian sehingga $y \sim x$, ditulis:

$$
[x]=\{y \in X \mid y \sim x\}
$$

Contoh 2.4. Relasi ekuivalen $\sim$ yang didefinisikan pada Contoh 2.1.1 untuk $n=3$ menghasilkan kelas ekuivalen yaitu:

$$
[x]=\left\{y \mid y=k x, x \in \mathbb{R}^{4} \backslash\{0\}, k \in \mathbb{R} \backslash\{0\}\right\} .
$$

\subsection{Himpunan Buka Pada Ruang Metrik}

Untuk mengetahui definisi himpunan buka pada ruang metrik terlebih dahulu akan dibahas definisi ruang metrik.

Definisi 2.5. [1] Misalkan X adalah suatu himpunan tak kosong. Suatu metrik pada himpunan $X$ adalah fungsi $d: X \times X \rightarrow \mathbb{R}$ yang mempunyai sifat sebagai berikut:

(1) $d(x, y) \geq 0$ untuk setiap $x, y \in X$ dan $d(x, y)=0 \Leftrightarrow x=y$ (sifat non-negatif),

(2) $d(x, y)=d(y, x)$ untuk setiap $x, y \in X$ (sifat simetri),

(3) $d(x, z) \leq d(x, y)+d(y, z)$ untuk setiap $x, y, z \in X$ (sifat ketaksamaan segitiga).

Pasangan terurut $(X, d)$ adalah ruang metrik dimana $X$ adalah himpunan tak kosong dan $d$ adalah fungsi metrik pada $X$.

Definisi 2.6. [4] Misalkan $X$ adalah ruang metrik, $x \in X$ dan $r>0$, maka bola buka dengan radius (jari-jari) $r$ berpusat di $x$ adalah

$$
B_{r}(x)=\{y \in X: d(x, y)<r\} .
$$


Suatu himpunan bagian $A$ dari ruang metrik $X$ dikatakan buka pada $X$ jika dan hanya jika untuk setiap titik $x \in A$ terdapat suatu bilangan positif $r$ sedemikian sehingga berlaku $B_{r}(x) \subseteq A$.

\subsection{Ruang Topologi}

Pada sub-bab ini akan dibahas beberapa definisi yang terkait pada ruang topologi.

Definisi 2.7. [3] Misalkan $X$ adalah suatu himpunan. Suatu topologi pada X adalah suatu koleksi $\mathcal{T}$ dari himpunan bagian $X$ yang memenuhi sifat-sifat berikut.

(1) $\emptyset \in \mathcal{T}, X \in \mathcal{T}$

(2) Jika $U_{1}, U_{2}, \cdots, U_{n}$ elemen dari $\mathcal{T}$ maka irisan berhingga dari $U_{1} \cap U_{2} \cap \cdots \cap U_{n}$ juga elemen dari $\mathcal{T}$.

(3) Jika $\left(U_{a}\right)_{(a \in A)}$ adalah semua keluarga dari elemen-elemen dari $\mathcal{T}$ (berhing-ga atau tak berhingga) dengan $A$ adalah himpunan indeks maka $\bigcup_{(a \in A)} U_{a}$ adalah elemen dari $\mathcal{T}$.

Dalam hal ini pasangan $(X, \mathcal{T})$ disebut ruang topologi, anggota-anggota dari $X$ disebut titik-titik dan himpunan-himpunan yang membentuk $\mathcal{T}$ disebut himpunanhimpunan bagian buka dari $X$.

Misalkan $X$ dan $Y$ adalah ruang topologi, $x \in X$, dan $f: X \rightarrow Y$ suatu fungsi, maka suatu lingkungan dari $x$ adalah suatu himpunan bagian buka $U$ dari $X$ yang memuat $x$. Fungsi $f$ dikatakan kontinu jika $f^{-1}(U)$ buka untuk setiap himpunan buka $U \subset Y[3]$.

Definisi 2.8. [3] Misalkan $X$ suatu ruang topologi. $X$ dikatakan suatu ruang Hausdorff jika diberikan sebarang pasangan dari titik-titik yang berbeda $p_{1}, p_{2} \in X$ maka terdapat lingkungan $U_{1}$ dari $p_{1}$ dan $U_{2}$ dari $p_{2}$ yang memenuhi $U_{1} \cap U_{2}=\emptyset$.

Definisi 2.9. [4] Suatu subkoleksi $\mathcal{B}$ dari topologi $\mathcal{T}$ pada suatu ruang topologi $S$ adalah suatu basis untuk topologi $\mathcal{T}$ jika untuk setiap himpunan buka $U$ dan titik $p$ di $U$, maka terdapat suatu himpunan buka $B \in \mathcal{B}$ sedemikian sehingga $p \in B \subset U$. Hal ini juga dapat disebut $\mathcal{B}$ membangun topologi $\mathcal{T}$ atau $\mathcal{B}$ adalah suatu basis untuk ruang topologi S. Suatu ruang topologi dikatakan second countable jika terdapat suatu countable basis.

Misalkan $X$ ruang topologi. Selimut buka (open cover) dari $X$ adalah koleksi $\mathcal{U}$ dari himpunan bagian buka dari $X$ yang gabungannya adalah $X$.

\subsection{Ruang Proyektif Riil}

Pada sub-bab ini akan dibahas mengenai ruang proyektif riil yang akan digunakan pada bab selanjutnya. Untuk memahami ruang proyektif riil terlebih dahulu dibahas mengenai definisi dan teorema terkait topologi kuosien.

Definisi 2.10. [3] Misalkan $X$ dan $Y$ adalah ruang topologi dan $p: X \rightarrow Y$ adalah pemetaan surjektif, maka topologi kuosien pada $Y$ yang ditentukan oleh p didefinisikan sebagai suatu himpunan bagian $U \subseteq Y$ buka jika dan hanya jika $p^{-1}(U)$ buka di $X$. 
Definisi 2.11. [4] Suatu relasi ekuivalen $\sim$ pada $S$ dikatakan buka dengan pemetaan $\pi: S \rightarrow S / \sim j i k a$ dan hanya jika untuk setiap himpunan buka $U$ di $S$ maka himpunan $\pi^{-1}(\pi(U))=\bigcup_{x \in U}[x]$ dari semua titik-titik ekuivalen pada beberapa titik di $U$ adalah buka.

Definisi 2.12. [4] Ruang proyektif riil $\mathbb{R}^{n}$ dapat dinyatakan sebagai ruang dari garis-garis yang melalui titik asal $\mathbb{R}^{n+1}$.

Untuk $n=3$, misalkan suatu relasi ekuivalen $\sim$ pada $\mathbb{R}^{4} \backslash\{0\}$ didefinisikan oleh $x \sim y \Leftrightarrow y=k x$, untuk $x \in \mathbb{R}^{4} \backslash\{0\}$ dan suatu $k \in \mathbb{R} \backslash\{0\}$ seperti pada Contoh 2.2, maka diperoleh kelas ekuivalen dari $x,[x]=\left[x_{1}: x_{2}: x_{3}: x_{4}\right]$ seperti pada Contoh 2.4. Ruang $\mathbb{R P}^{3}$ didefinisikan sebagai himpunan semua kelas ekuivalen $[x]$ yaitu koleksi dari himpunan bagian dari $\mathbb{R}^{4} \backslash\{0\}$ yang saling lepas dimana gabung-annya adalah $\mathbb{R}^{3} \backslash\{0\}$. Secara notasi, didefinisikan oleh $\mathbb{R P}^{3}=\mathbb{R}^{4} \backslash\{0\} / \sim$. Didefinisikan pemetaan $\pi: \mathbb{R}^{4} \backslash\{0\} \longrightarrow \mathbb{R P}^{3}$ oleh $\pi(x)=[x]$. Pemetaan ini menghasilkan topologi kuosien pada $\mathbb{R P}^{3}$ yang didefinisikan sebagai berikut: himpunan bagian $U$ di $\mathbb{R P}^{3}$ buka jika dan hanya jika $\pi^{-1}(U)$ buka di $\mathbb{R}^{4} \backslash\{0\}$, keluarga $\mathcal{T}$ dari himpunanhimpunan buka ini memenuhi definisi topologi. $\mathbb{R P}^{4}$ bersama-sama dengan topologi $\mathcal{T}$ disebut dengan ruang kuosien. [4]

Proposisi 2.13. [4] Relasi ekuivalen $\sim$ pada $\mathbb{R}^{n+1} \backslash\{0\}$ pada definisi $\mathbb{R P}^{n}$ adalah relasi ekuivalen buka.

Akibat 2.14. [4] Ruang proyektif riil $\mathbb{R P}^{n}$ adalah ruang second countable.

Definisi 2.15. [3] Suatu ruang topologi $M$ dikatakan Euklidis berdimensi $\boldsymbol{n}$ lokal apabila untuk setiap $x \in M$ terdapat lingkungan $U$ dari $x$ dengan $U \subseteq M$ yang homeomorfis terhadap suatu himpunan bagian buka dari $\mathbb{R}^{n}$.

Contoh 2.16. Ruang $\mathbb{R P}^{3}$ bersifat Euklidis lokal. Ini dapat ditunjukkan dengan langkah sebagai berikut.

(a) Menentukan suatu lingkungan $U_{i}$ dari $[x]$ untuk setiap $[x] \in \mathbb{R P}^{3}$.

Misalkan $\tilde{U}_{i} \subseteq \mathbb{R}^{4} \backslash\{0\}$ dimana $x_{i} \neq 0$ untuk setiap $i=1,2,3,4$ dan $U_{i}=$ $\pi\left(\tilde{U}_{i}\right) \subseteq \mathbb{R P}^{3}$. Karena $\mathbb{R P}^{3}$ adalah himpunan dari kelas ekuivalen $[x]$ dengan topologi kuosien yang ditentukan oleh $\pi$, maka $\tilde{U}_{i}, i=1,2,3,4$ adalah buka di $\mathbb{R}^{4} \backslash\{0\}$. Karena $\tilde{U}_{i}=\pi^{-1}\left(U_{i}\right)$ buka di $\mathbb{R}^{4} \backslash\{0\}$ maka $U_{i}$ adalah buka di $\mathbb{R P}^{3}$.

(b) Menentukan suatu himpunan bagian buka $\tilde{U}_{i} \subseteq \mathbb{R}^{3}$.

Misalkan $U_{i}=\left\{[x]=\left[x_{1}: x_{2}: x_{3}: x_{4}\right] \in \mathbb{R P}^{3} \mid x_{i} \neq 0\right\}$ dengan $i=1,2,3,4$. Telah ditunjukkan bahwa $U_{i}$ buka di $\mathbb{R P}^{3}$. Dikontruksi pemetaan $\varphi_{i}: U_{i} \rightarrow \mathbb{R}^{3}$ dengan $i=1,2,3,4$ yang didefinisikan oleh

$$
\begin{aligned}
& \varphi_{i}([x])=\left(\frac{x_{2}}{x_{1}}, \frac{x_{3}}{x_{1}}, \frac{x_{4}}{x_{1}}\right)=\left(u_{1}, u_{2}, u_{3}\right), \varphi_{2}([x])=\left(\frac{x_{1}}{x_{2}}, \frac{x_{3}}{x_{2}}, \frac{x_{4}}{x_{2}}\right)=\left(v_{1}, v_{2}, v_{3}\right), \\
& \varphi_{3}([x])=\left(\frac{x_{1}}{x_{3}}, \frac{x_{2}}{x_{3}}, \frac{x_{4}}{x_{3}}\right)=\left(w_{1}, w_{2}, w_{3}\right), \varphi_{4}([x])=\left(\frac{x_{1}}{x_{4}}, \frac{x_{2}}{x_{4}}, \frac{x_{3}}{x_{4}}\right)=\left(t_{1}, t_{2}, t_{3}\right) .
\end{aligned}
$$

Pemetaan ini terdefinisi dengan baik karena nilainya tidak berubah oleh perkalian $x$ dengan suatu konstanta taknol. 
Perhatikan bahwa $\varphi_{i}\left(U_{i}\right), i=1,2,3,4$ merupakan himpunan bagian buka di $\mathbb{R}^{3}$.

(c) Menentukan suatu homeomorfisma $\varphi_{i}: U_{i} \rightarrow \tilde{U}_{i}$.

Misalkan $V_{i}=\varphi_{i}\left(U_{i}\right)$. Akan ditunjukkan pemetaan $\varphi_{i}: U_{i} \rightarrow V_{i}, i=1,2,3,4$ adalah suatu homeomorfisma. Didefinisikan $\phi_{i}: V_{i} \longrightarrow U_{i}$ dengan

$$
V_{i}=\left\{y \in \mathbb{R}^{3} \mid y=\varphi_{i}([x]),[x] \in U_{i}\right\}
$$

dengan $i=1,2,3,4$ oleh

$$
\begin{aligned}
& \phi_{1}\left(u_{1}, u_{2}, u_{3}\right)=\left[1: u_{1}: u_{2}: u_{3}\right], \phi_{2}\left(v_{1}, v_{2}, v_{3}\right)=\left[v_{1}: 1: v_{2}: v_{3}\right] \\
& \phi_{3}\left(w_{1}, w_{2}, w_{3}\right)=\left[w_{1}: w_{2}: 1: w_{3}\right], \phi_{4}\left(t_{1}, t_{2}, t_{3}\right)=\left[t_{1}: t_{2}: t_{3}: 1\right]
\end{aligned}
$$

sehingga

$$
\begin{gathered}
\left(\varphi_{1} \circ \phi_{1}\right)\left(u_{1}, u_{2}, u_{3}\right)=\varphi_{1}\left(\phi_{1}\left(u_{1}, u_{2}, u_{3}\right)\right) \\
=\varphi_{1}\left(\left[1: u_{1}: u_{2}: u_{3}\right]\right) \\
=\varphi_{1}\left(\left[1: \frac{x_{2}}{x_{1}}: \frac{x_{3}}{x_{1}}: \frac{x_{4}}{x_{1}}\right]\right) \\
=\varphi_{1}\left(\left[x_{1}: x_{2}: x_{3}: x_{4}\right]\right) \\
=\left(u_{1}, u_{2}, u_{3}\right) .
\end{gathered}
$$

Dengan cara yang sama, dapat dibuktikan juga untuk $i=2, i=3$ dan $i=4$. Akibatnya $\left(\varphi_{i} \circ \phi_{i}\right)=I d_{V_{i}}$ dan $\left(\phi_{i} \circ \varphi_{i}\right)=I d_{U_{i}}, i=1,2,3,4$. Jadi terbukti $\phi_{i}=\varphi_{i}^{-1}$ untuk setiap $i=1,2,3,4$.

Pemetaan $\varphi_{i}$ surjektif dan kontinu. Karena $\varphi_{i}$ dan $\phi_{i}$ kontinu maka $\varphi_{i}$ untuk setiap $i=1,2,3,4$ adalah homeomorfisma.

Dari (a),(b), dan (c) diperoleh bahwa $\mathbb{R P}^{2}$ bersifat Euklidis berdimensi 3 lokal.

\section{Manifold Kompleks}

Pada bab ini akan dikaji mengenai ruang proyektif kompleks $(\mathbb{C P})$ sebagai manifold kompleks berdimensi 1 . Sebelumnya perlu dibuktikan terlebih dahulu bahwa $\mathbb{C P}$ merupakan manifold smooth berdimensi 2 dengan struktur smooth yang analog dengan yang ada pada $\mathbb{R P}^{3}$ dan perlu dibahas juga bahwa $\mathbb{R P}^{3}$ adalah manifold topologi. Selain itu juga dibahas mengenai fungsi holomorfik yang sangat diperlukan pada penentuan atlas holomorfik.

\subsection{Ruang Proyektif Riil $\left(\mathbb{R P}^{3}\right)$ sebagai Manifold Topologi}

Manifold topologi adalah suatu ruang topologi dengan tiga sifat tertentu yang menggambarkan bahwa ruang tersebut secara lokal terlihat seperti suatu ruang Euklidis.

Definisi 3.1. [3] Misalkan $M$ suatu ruang topologi. $M$ dikatakan manifold topologi berdimensi $n$ atau n-manifold topologi jika memenuhi sifat-sifat berikut:

(1) $M$ adalah suatu ruang Hausdorff. 
(2) $M$ adalah second countable, yaitu terdapat suatu basis terhitung (counta-ble basis) untuk topologi $M$.

(3) $M$ adalah Euklidis berdimensi $n$ secara lokal, yaitu sebarang titik di $M$ mempunyai suatu lingkungan yang homeomorfisma pada suatu himpunan bagian buka $d i \mathbb{R}^{n}$.

Contoh 3.2. Misalkan pemetaan $\pi: \mathbb{R}^{4} \backslash\{0\} \rightarrow \mathbb{R P}^{3}$ didefinisikan dengan memetakan setiap $x \in \mathbb{R}^{4} \backslash\{0\}$ ke $[x] \in \mathbb{R P}^{3}$. Ruang proyektif rill $\mathbb{R P}^{3}$ merupakan manifold topologi berdimensi 3. Ruang $\mathbb{R P}^{3}$ adalah ruang Hausdorff. Hal ini dapat dibuktikan dengan menggunakan Definisi 2.10. Berdasarkan Akibat 2.16 maka ruang $\mathbb{R P}^{3}$ adalah ruang second countable dan $\mathbb{R P}^{3}$ bersifat Euklidis lokal. Hal ini telah dibuktikan pada Contoh 2.18.

\subsection{Ruang Proyektif Riil $\left(\mathbb{R P}^{3}\right)$ sebagai Manifold Smooth}

Misalkan $U$ dan $V$ adalah himpunan bagian buka dari ruang Euklidis $\mathbb{R}^{n}$ dan $\mathbb{R}^{m}$ berturut-turut. Suatu fungsi $f: U \rightarrow V$ dikatakan smooth (atau $C^{\infty}$ atau terdiferensial secara tak berhingga) jika semua komponen fungsinya memiliki turunan parsial kontinu dari semua orde (tingkat). Jika fungsi $f$ adalah bijektif dan fungsi $\mathrm{f}$ dan $f^{-1}$ adalah smooth, maka $f$ adalah diffeomorfisma [3].

Misalkan $M$ adalah suatu $n$-manifold topologi. Suatu chart pada $M$ adalah pasangan $(U, \varphi)$, dimana $U$ adalah himpunan bagian buka dan $\varphi: U \rightarrow U^{\prime}$ adalah pemetaan homeomorfisma dari $U$ ke suatu himpunan bagian buka $U^{\prime}=\varphi(U) \subseteq \mathbb{R}^{n}$. Jika $(U, \varphi)$ dan $(V, \psi)$ adalah dua chart yang berlaku $U \cap V \neq \emptyset$, maka fungsi komposisi $\psi \circ \varphi^{-1}: \varphi(U \cap V) \rightarrow \psi(U \cap V)$ dikatakan pemetaan transisi dari $\varphi$ ke $\psi$. Dua chart $(U, \varphi)$ dan $(V, \psi)$ dikatakan smoothly compatible, jika $U \cap V=\emptyset$ atau pemetaan transisi $\psi \circ \varphi^{-1}$ adalah diffeomorfisma. Suatu atlas dari $M$ adalah koleksi dari chart yang domainnya menutupi $M$. Suatu atlas $\mathcal{A}$ dikatakan atlas smooth, jika setiap dua chart pada $\mathcal{A}$ adalah smoothly compatible dengan yang lainnya [3].

Definisi 3.3. [3] Misalkan $M$ adalah manifold topologi, maka suatu struktur smooth di $M$ adalah maksimal atlas smooth. Suatu manifold smooth adalah pasangan $(M, \mathcal{A})$, dimana $M$ adalah manifold topologi dan $\mathcal{A}$ adalah struktur smooth di $M$

Contoh 3.4. Ruang proyektif $\mathbb{R P}^{3}$ adalah manifold smooth karena $\mathbb{R P}^{3}$ adalah manifold topologi yang telah ditunjukkan pada Contoh 3.2 dan terdapat suatu atlas smooth $\mathcal{A}=\left\{\left(U_{i}, \varphi_{i}\right)\right\}$ dimana $U_{i}$ adalah himpunan bagian buka pada $\mathbb{R P}^{3}$ dan $\varphi_{i}: U_{i} \rightarrow \varphi_{i}\left(U_{i}\right)$ adalah pemetaan homeomorfisma dan pemetaan transisi $\varphi_{i} \circ \varphi_{j}^{-1}: \varphi_{j}\left(U_{i} \cap U_{j}\right) \rightarrow \varphi_{i}\left(U_{i} \cap U_{j}\right)$ untuk $i, j=1,2,3,4$ dengan $i \neq j$ adalah diffeomorfisma yang menunjukkan bahwa terdapat struktur smooth di $\mathbb{R P}^{3}$.

\subsection{Manifold Kompleks}

Pada sub-bab ini akan dibahas definisi manifold kompleks. Sebelumnya terlebih dahulu dibahas beberapa definisi terkait dengan manifold kompleks. 
Definisi 3.5. [2] Misalkan $U \subset \mathbb{C}^{n}$ himpunan bagian buka dan $f: U \rightarrow \mathbb{C}$ adalah suatu fungsi terdiferensial kontinu. Fungsi $f$ dikatakan holomorfik jika berlaku persamaan Cauchy Riemann untuk semua koordinat $z_{j}=x_{j}+i y_{j}$ yaitu,

$$
\frac{\partial u}{\partial x_{j}}=\frac{\partial v}{\partial y_{j}} \operatorname{dan} \frac{\partial u}{\partial y_{j}}=-\frac{\partial v}{\partial x_{j}}, j=1,2, \cdots, n .
$$

Suatu pemetaan $f: U \rightarrow V$ antara dua himpunan bagian buka $U, V \subset \mathbb{C}^{n}$ adalah biholomorfik jika dan hanya jika $f$ adalah bijektif dan holomorfik serta fungsi inversnya $f^{-1}: V \rightarrow U$ adalah holomorfik.

Definisi 3.6. [2] Misalkan $M$ adalah manifold topologi. Suatu chart kompleks $(U, \varphi)$ dari $M$ adalah pasangan himpunan bagian buka $U \subseteq M$ dan $\varphi: U \rightarrow V$ adalah homeomorfisma dari $U$ ke suatu himpunan bagian buka $V=\varphi(U) \subset \mathbb{C}^{n}$. Dua chart kompleks $\left(U_{i}, \varphi_{i}\right),\left(U_{j}, \varphi_{j}\right)$ adalah compatible (sepadan) jika pemetaan $\varphi_{i j}:=\varphi_{i} \circ \varphi_{j}^{-1}: \varphi_{j}\left(U_{i} \cap U_{j}\right) \rightarrow \varphi_{i}\left(U_{i} \cap U_{j}\right)$ adalah holomorfik. Pemetaan $\varphi_{i j}$ disebut pemetaan tansisi. Suatu atlas holomorfik dari $M$ adalah koleksi $A=\left\{\left(U_{i}, \varphi_{i}\right)\right\}$ dari chart kompleks, sedemikian sehingga $X=\bigcup_{i} U_{i}$ dan semua pemetaan transisi $\varphi_{i j}$ adalah biholomorfik. Suatu struktur kompleks pada $M$ adalah suatu atlas holomorfik maksimal $A=\left\{\left(U_{i}, \varphi_{i}\right)\right\}_{i \in I}$. Pengertian maksimal disini adalah jika $(U, \varphi)$ adalah lokal chart kompleks dan $(U, \varphi)$ adalah compatible dengan $\left(U_{i}, \varphi_{i}\right), \forall i \in$ $I \operatorname{maka}(U, \varphi) \in A$.

Definisi 3.7. [2] Suatu manifold kompleks yang berdimensi n adalah suatu manifold smooth riil berdimensi $2 n$ yang dilengkapi dengan struktur kompleks.

\subsection{Ruang Proyektif Kompleks (CP) sebagai Manifold Kompleks Berdimensi 1}

Ruang proyektif kompleks $\mathbb{C P}$ adalah ruang dari semua garis kompleks yang melalui titik asal $\mathbb{C}^{2}$. Misalkan $\sim$ adalah relasi ekuivalen dari $z=\left(z_{1}, z_{2}\right) \in \mathbb{C}^{2} \backslash\{0\}$ pada $\mathbb{C}^{2} \backslash\{0\}$ yang didefinisikan sebagai $\left(z_{1}, z_{2}\right) \sim\left(\lambda z_{1}, \lambda z_{2}\right)$ untuk $\lambda \in \mathbb{C} \backslash\{0\}$, maka kelas ekuivalen $z,[z]=\left[z_{1}: z_{2}\right]$. Akibatnya, $\mathbb{C P}$ didefinisikan juga sebagai himpunan dari semua kelas ekuivalen $[z]$ yaitu koleksi dari himpunan bagian dari $\mathbb{C}^{2} \backslash\{0\}$ yang saling asing dimana gabungannya adalah $\mathbb{C}^{2} \backslash\{0\}$. Secara notasi, didefinisikan sebagai $\mathbb{C P}=\mathbb{C}^{2} \backslash\{0\} / \sim$.

Didefinisikan pemetaan $p: \mathbb{C}^{2} \backslash\{0\} \rightarrow \mathbb{C P}$. Pemetaan ini menghasilkan topologi kuosien pada $\mathbb{C P}$ yang didefinisikan dengan himpunan buka $U$ di $\mathbb{C P}$ buka jika dan hanya jika $p^{-1}(U)$ buka di $\mathbb{C}^{2} \backslash\{0\}$, keluarga $\mathcal{T}$ dari himpunan-himpunan buka ini memenuhi definisi topologi. Ruang $\mathbb{C P}$ bersama-sama dengan topologi $\mathcal{T}$ disebut dengan ruang kuosien. Karena $\mathbb{C P}$ adalah ruang dari semua garis kompleks yang melalui titik asal $\mathbb{C}^{2}\left(\equiv \mathbb{R}^{4}\right)$, sedangkan $\mathbb{R} \mathbb{P}^{3}$ adalah ruang dari semua garis lurus yang melalui $\mathbb{R}^{4}$ maka dengan menggunakan korespondensi satu-satu, jika $z \in \mathbb{C}^{2}$ maka $z$ dapat diidentifikasi dengan

$$
z=\left(z_{1}, z_{2}\right)=\left(x_{1}+i y_{1}, x_{2}+i y_{2}\right) \leftrightarrow\left(x_{1}, y_{1}, x_{2}, y_{2}\right)
$$

sehingga struktur smooth di $\mathbb{C P}$ dapat ditentukan dengan menganalogikan struktur smooth di $\mathbb{R P}^{3}$ dan semua sifat manifold topologi seperti Hausdorff untuk $\mathbb{C P}$ dapat 
ditentukan dengan cara yang sama dengan $\mathbb{R P}^{3}$. Jadi, $\mathbb{C P}$ adalah manifold smooth berdimensi 2. Karena setiap titik di $\mathbb{C P}$ berbeda satu sama lain oleh faktor $\lambda$, maka pemetaan $p$ menghasilkan suatu topologi kuosien pada $\mathbb{C P}$ sehingga $p$ adalah kontinu. Misalkan $U_{k}=\left\{\left[z_{1}: z_{2}\right] \in \mathbb{C P} \mid z_{k} \neq 0\right\},(k=1,2)$ adalah suatu himpunan bagian buka dari $\mathbb{C P}$ dan koleksi $\left\{U_{k}\right\}_{k \in\{1,2\}}$ adalah suatu selimut buka dari $\mathbb{C P}$. Untuk setiap $U_{k}$ didefinisikan suatu pemetaan bijektif $\varphi_{k}: U_{k} \rightarrow \mathbb{C}$ oleh

$$
\varphi_{1}\left(\left[z_{1}: z_{2}\right]\right)=\frac{z_{2}}{z_{1}}, \varphi_{2}\left(\left[z_{1}: z_{2}\right]\right)=\frac{z_{1}}{z_{2}}
$$

sehingga $\varphi_{k}$ adalah pemetaan homeomorfisma sesuai definisi di atas. Oleh karena itu, jika $U_{1} \cap U_{2} \neq 0$ dan misalkan

$$
\frac{z_{2}}{z_{1}}=s_{1} \text { dan } \frac{z_{1}}{z_{2}}=s_{2}
$$

maka diperoleh pemetaan transisi $\varphi_{k} \circ \varphi_{j}^{-1}\left(U_{k} \cap U_{j}\right): \varphi_{j}\left(U_{k} \cap U_{j}\right) \rightarrow \varphi_{k}\left(U_{k} \cap U_{j}\right)$ untuk setiap $k, j=1,2$ dan $k \neq j$ yaitu

$$
\left(\varphi_{2} \circ \varphi_{1}^{-1}\right)\left(s_{1}\right)=\frac{1}{s_{1}} \operatorname{dan}\left(\varphi_{1} \circ \varphi_{2}^{-1}\right)\left(s_{2}\right)=\frac{1}{s_{2}} .
$$

Karena $\varphi_{k}$ adalah fungsi bijektif maka $\varphi_{k}^{-1}$ adalah fungsi bijektif untuk setiap $k=$ 1,2 maka $\varphi_{2} \circ \varphi_{1}^{-1}$ dan $\varphi_{1} \circ \varphi_{2}^{-1}$ adalah fungsi bijektif dan saling invers. Karena $\varphi_{2} \circ \varphi_{1}^{-1}$ dan $\varphi_{1} \circ \varphi_{2}^{-1}$ memenuhi persamaan Cauchy Riemann maka $\varphi_{2} \circ \varphi_{1}^{-1}$ dan $\varphi_{1} \circ \varphi_{2}^{-1}$ merupakan fungsi holomorfik. Oleh karena itu, pemetaan transisi $\varphi_{k j}$ adalah biholomorfik sehingga koleksi $A=\left\{\left(U_{i}, \varphi_{i}\right)\right\}$ merupakan suatu atlas holomorfik yang mendefinisikan suatu struktur kompleks pada $\mathbb{C P}$. Jadi, $(\mathbb{C P}, A)$ adalah manifold kompleks berdimensi 1 .

\section{Ucapan Terima Kasih}

Penulis mengucapkan terima kasih kepada Bapak Dr. Jenizon, Ibu Radhiatul Husna, M. Si, Bapak Dr. Mahdhivan Syafwan yang telah memberikan kritik dan saran untuk tulisan ini.

\section{Kesimpulan}

Ruang $\mathbb{C P}$ adalah suatu manifold kompleks berdimensi 1 , karena $\mathbb{C P}$ adalah manifold smooth berdimensi 2 dan terdapat suatu atlas holomorfik $A=\left\{\left(U_{k}, \varphi_{k}\right)\right\}$ untuk $k=1,2$ yang menunjukkan suatu struktur kompleks pada $\mathbb{C P}$.

\section{Daftar Pustaka}

[1] Brown A. dan A. Page. 1970. Elements of Functional Analysis. Van Nostrand Reinhold Company, London.

[2] Huybrochts, Daniel. 2004. Complex Geometry An Introduction. Springer, Berlin.

[3] Lee, John M. 2013. Introduction to Smooth Manifold. Second Edition. Springer, New York.

[4] Tu, Loring W. 2011. An Introduction to Manifold. Second Edition. Springer, New York. 